\title{
Comparative Study of Functional Food Regulations in Japan and Globally
}

\author{
Mohamed Farid ${ }^{1, *}$, Kota Kodama ${ }^{1, *}$, Teruyo Arato ${ }^{2}$, Takashi Okazaki ${ }^{3}$, \\ Tetsuaki Oda ${ }^{1}$, Hideko Ikeda ${ }^{4} \&$ Shintaro Sengoku ${ }^{5}$ \\ ${ }^{1}$ Graduate School of Technology Management, Ritsumeikan University, Osaka, Japan \\ ${ }^{2}$ Hokkaido University Hospital, Sapporo, Japan \\ ${ }^{3}$ Leave a Nest Co., Ltd., Tokyo, Japan \\ ${ }^{4}$ The Japanese Institute for Health Food Standards (JIHFS), Tokyo, Japan \\ ${ }^{5}$ School of Environment and Society, Tokyo Institute of Technology, Tokyo, Japan \\ Correspondence: Graduate School of Technology Management, Ritsumeikan University, 2-150, Iwakuracho, \\ Ibaraki, Osaka, Japan. Tel: 81-72-665-2448. E-mail: kkodama@fc.ritsumei.ac.jp \\ "Shared first authorship, these authors contributed equally to this work.
}

Received: March 27, 2019 Accepted: April 24, 2019 Online Published: May 13, 2019

doi:10.5539/gjhs.v11n6p132 URL: https://doi.org/10.5539/gjhs.v11n6p132

\begin{abstract}
Since its inception in Japan, functional food has continued to deliver a true added value to a wide spectrum of customers, especially in aging subpopulations. Japanese companies have strong "R\&D" capabilities and strong know-how in the field of functional foods. They have the opportunity to grow overseas by promoting and marketing their products. The main challenge is to understand the foreign markets and their regulations to be able to promote Japanese products overseas. To achieve this goal, the study reports a scientific review of the relevant literature and official legislative reports published by the authorized entities in several countries to create a comparison between the rules and regulations in different countries such as China, the European Union, South Korea, Singapore, Taiwan, and the United States. The study results provide suggestions for entry strategies to recommended foreign markets based on regulatory situations. The study also provides a comparison for the different functional food regulations in Japan (FOSHU, FNFC, FFC), along with an introduction for the new local government certification system.
\end{abstract}

Keywords: functional food, aged population, regulation, business expansion, entrepreneurial support

\section{Introduction}

Food is a necessity for human life. It provides nutrients and energy for our daily life. However, food has transformed into "functional food" that alters health benefits and nutrition. Functional food now has advanced to the point at which it can be designed to enhance public health and to reduce the probability of having specific types of diseases. Functional food may be defined as food or drinks that have boosted nutrients such as vitamins, fiber, protein, mineral or other components that have a functional purpose. Functional foods can work in two different ways: (1) by boosting existing ingredients or (2) by adding one or more new ingredients to enhance functions not found in the original food (Hasler, 2002).

Functional food manufacturers follow specific processes to assure the creation of products with true values. Many regulatory authorities around the world craft strict and detailed regulations and standards to ensure the efficiency and safety of the foods. The regulatory bodies also may study if the products provide true value for consumers. Regulations vary from country to country, which makes exporting functional foods a challenging task, especially if the regulations are not clear, or if the products have not been customized to suit the regulation of the importing country.

Since its inception in Japan, functional food has continued to deliver a true added value for a wide spectrum of customers, especially among senior citizens. In the 1980s, the term, "functional foods," was introduced in Japan, followed by legislation for it. Functional food has become important in Japanese economics and society. With 
increasing medical care costs and the resulting financial burdens that Japan is facing, including welfare programs for senior citizens and others with chronic diseases, the adoption of healthy and functional food at the earliest possible age can limit the possibility of acquiring diet-related diseases, thus reducing the cost of national health expenditures (Bagchi, 2014).

Table 1. Estimates of national medical care expenditures in Japan

\begin{tabular}{lllc}
\hline Year & $\begin{array}{l}\text { Total Expenditure } \\
\text { (Thousand JPY) }\end{array}$ & $\begin{array}{l}\text { Increase compared } \\
\text { to the previous year (\%) }\end{array}$ & $\begin{array}{l}\text { Expenditure per capita } \\
\text { (Thousand JPY) }\end{array}$ \\
\hline 1985 & 16.02 & 6.1 & 132.3 \\
1986 & 17.07 & 6.6 & 140.3 \\
1987 & 18.08 & 5.9 & 147.8 \\
1988 & 18.76 & 3.8 & 152.8 \\
1989 & 19.73 & 5.2 & 160.1 \\
1990 & 20.61 & 4.5 & 166.7 \\
1991 & 21.83 & 5.9 & 176.0 \\
1992 & 23.48 & 7.6 & 188.7 \\
1993 & 24.36 & 3.8 & 195.3 \\
1994 & 25.79 & 5.9 & 206.3 \\
1995 & 26.96 & 4.5 & 214.7 \\
2016 & 42.14 & 0.5 & 332.0 \\
\hline
\end{tabular}

Source: Ministry of Health, Labour and Welfare annual reports 1985 - 2016.

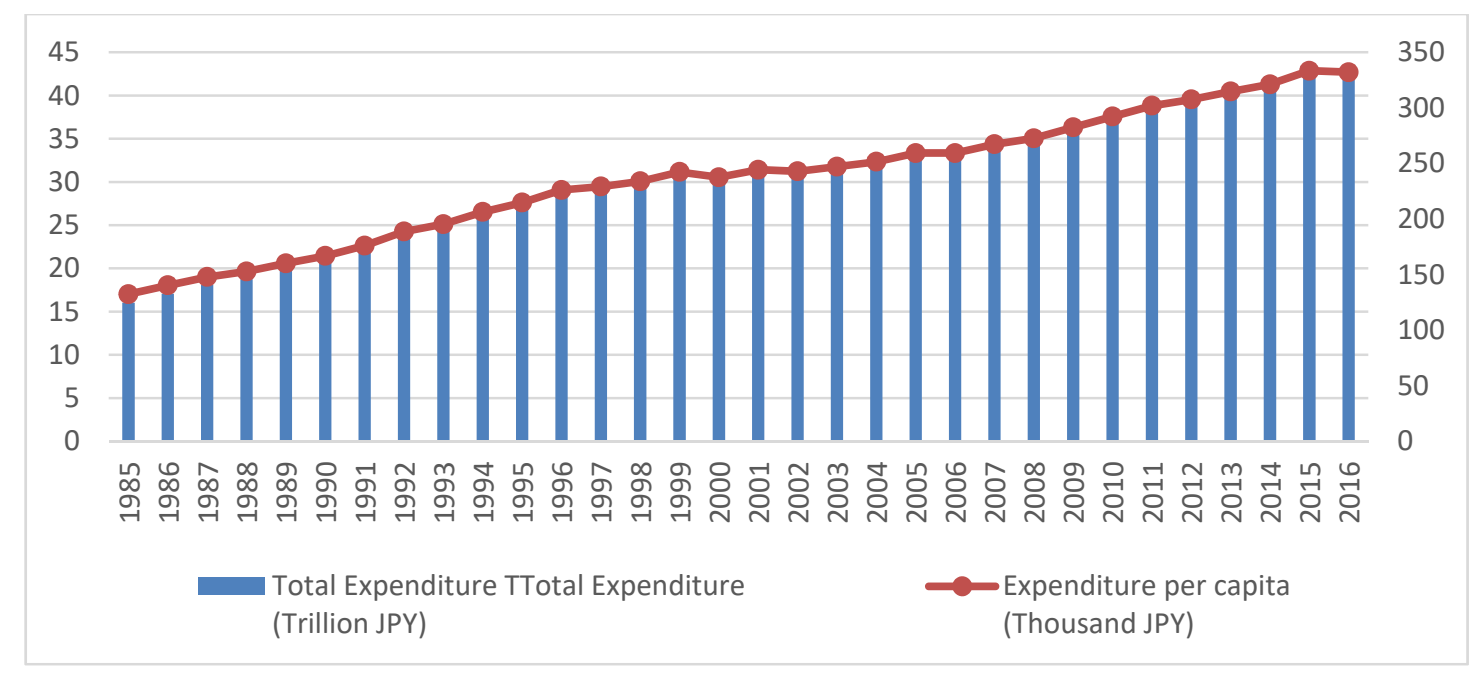

Figure 1. Estimates of National Medical Care Expenditures in Japan (1985-2016)

The term Food for Specified Health Use FOSHU was created by the Japanese Ministry of Health, Labour and Welfare in an effort to create accurate regulations to accredit functional food products and validate their commercialization.

The global market share of functional foods is growing rapidly. The market has registered a revenue of 300 billion USD in 2017 and is expected to increase to 440 \$B in 2022. The Asia-Pacific region has 34\% market share, followed by North America with 25\%, Latin America with 17\%, Western Europe with 16\%, Eastern Europe with $3 \%$, the Middle East and Africa with 3\%, and Australia and New Zealand with 2\%. While the USA has the highest market share by country, the Asia-Pacific region has more market share by region. Currently, Japan leads the region with a market size ranging between $\$ 30 \mathrm{~B}$ and $\$ 40 \mathrm{~B}$. However, the American market is growing rapidly with rates exceeding $10 \%$ a year (Euro Monitor, 2013). In contrast, the market in Japan shows a much lower growth 
level of less than $2 \%$ a year.

\subsection{Functional Food Markets}

In comparing the key demographics of potential markets for functional food, we take the age dependency ratio as an important measure. The age dependency ratio is the ratio of older dependents (people older than 64) to the working-age population (those aged 15-64). It measures the proportion of the elderly segment of society compared to those of working age. A large ratio indicates that a large segment of the population depends on the working population to fund the medical and other needs of seniors. In societies with high elderly population ratios, innovative measures must be taken to reduce expenditures for social services without decreasing the level of service.

A comparison between the age dependency ratio for the years 1967 and 2017 has been created to assess changes over the past fifty years. In general, the countries in our comparison all show increases in the elderly dependency varies widely from one country to another. The lowest increase was in the United States, with an increase from $15.9 \%$ in 1967 to $23.4 \%$ in 2017 , a jump of $47 \%$. In stark contrast, the highest increase occurred in Japan, from $9.3 \%$ in 1967 to $45 \%$ in 2017 - a massive increase of $383.9 \%$. The EU has increased by $78.4 \%$, Korea by $193.8 \%$, Taiwan by $170 \%$, China by $131.3 \%$, and Singapore by $244.2 \%$. While the EU has a ratio of $30.5 \%$ for 2017 , (higher than the Asian countries except for Japan), Europe has experienced a low level of increase over the past 50 years compared to Asian countries. This implies that the Asian countries, in general, saw significant demographic change during the past few decades (World Bank, 2017).

We believe that the Asian markets for functional foods will continue to grow in order to face the high medical and social expenditures associated with these changes. Also, markets such as China, with a total population of 1.37 billion, already have tremendous opportunities in this arena, exacerbated by the rapid increase of the age dependency ratio (14.8\% in 2017, with a fifty-year jump of $131.3 \%$ ). The growing elderly dependency ratio undoubtedly comes, in part, from healthcare services that have increased the average rate of life expectancy. In Japan, average life expectancy reached to 87 years for females and 81 years for males in 2017.

Table 2. Comparison of functional food markets across the World (World Bank 2016)

\begin{tabular}{llllllll}
\hline Variable & $E U$ & US & Korea & Taiwan & China & Singapore & Japan \\
\hline Population (M) & 511.2 & 323.4 & 51.2 & 23.5 & $1,378.6$ & 5.6 & 126.9 \\
GDP (\$.T.) & 16.4 & 18.6 & 1.4 & 0.4 & 11.1 & 0.3 & 4.9 \\
GDP per Capita (\$.K.) & 32.2 & 57.5 & 27.6 & 25.5 & 8.1 & 55.2 & 38.9 \\
Life Expectancy (year) & 80.6 & 78.6 & 82.0 & 80.4 & 76.2 & 82.7 & 83.9 \\
Age dependency ratio, old* (\%) Year 2017 & 30.5 & 23.4 & 19.1 & 18.9 & 14.8 & 17.9 & 45.0 \\
Age dependency ratio, old* (\%) Year 1967 & 17.1 & 15.9 & 6.5 & 7.0 (est.) & 6.4 & 5.2 & 9.3 \\
Increase in age dependency over 50 years (\%) & 78.4 & 47.2 & 193.8 & 170 & 131.3 & 244.2 & 383.9 \\
\hline
\end{tabular}

* Age dependency ratio, old, is the ratio of older dependents (people older than 64) to the working-age population (ages 15-64).

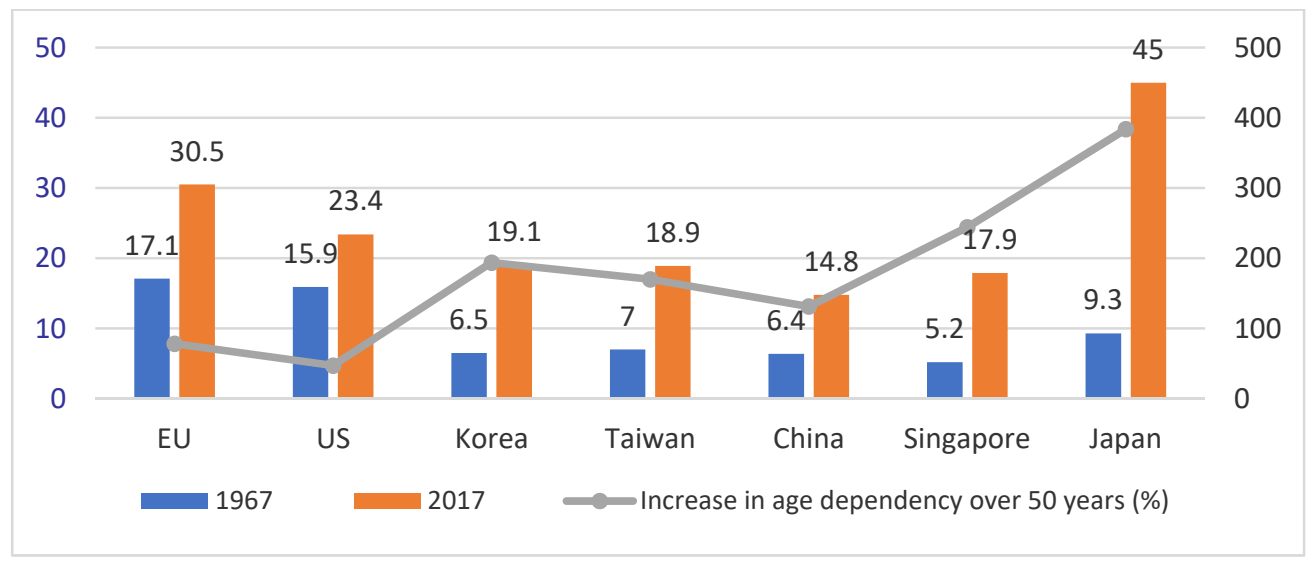

Figure 2. The development of the age dependency ratio over the past 50 years (\%) 


\subsection{Major Functional Food: Global Players}

The functional food industry is a multibillion-dollar industry worldwide that had over 300 billion USD in revenue in 2017, with high expectations to grow over the coming years (Daliri,2015). Due to the strict regulations that control functional food certifications, we can see that the major players in this market are large enterprises (see Table 3 below) that have the resources to satisfy all the requirements and market the products globally. The major players in this market are mainly concentrated in the USA and Europe, and they have global operations that allow manufacturers to distribute the products in different countries utilizing the economy of scale and economy of scope principles to maximize the efficiency of the operations.

Table 3. Major players in the functional food global market

\begin{tabular}{lllll}
\hline Company & HQ Country & Year of establishment & Annual Revenue & No. of employees \\
\hline Amway & USA & 1959 & $\$ 8.6 \mathrm{~B}$ & 17,000 \\
Archer Daniels Midland Company. & USA & 1902 & $\$ 62.3 \mathrm{~B}$ & 32,300 \\
Arla Foods. & Denmark & 2000 & $€ 10.3 \mathrm{~B}$ & 18,700 \\
BASF SE. & Germany & 1865 & $€ 64.4 \mathrm{~B}$ & 115,000 \\
Cargill Inc. & USA & 1865 & $\$ 114.6 \mathrm{~B}$ & 150,000 \\
DSM NV. & Netherlands & 1902 & $€ 8.6 \mathrm{~B}$ & 21,000 \\
General Mills Inc. & USA & 1856 & $\$ 15.6 \mathrm{~B}$ & 38,000 \\
Herbalife & USA & 1980 & $\$ 4.4 \mathrm{~B}$ & 8,000 \\
Ingredion Incorporated & USA & 1906 & $\$ 5.8 \mathrm{~B}$ & 11,000 \\
Kerry Group PLC. & Ireland & 1972 & $€ 6.1 \mathrm{~B}$ & 24,000 \\
Nestlé & Switzerland & 1867 & $€ 79.6 \mathrm{~B}$ & 323,000 \\
Tate \& Lyle PLC. & UK & 1921 & $£ 2.7 \mathrm{~B}$ & 4,100 \\
\hline
\end{tabular}

Source: Data has been gathered via the official websites of the companies and Bloomberg database.

\section{Research context}

\subsection{Problem}

Although that the Japanese market has low growth level, the companies in this market have strong research and development (R\&D) capabilities and strong knowledge in the field of functional foods. There is a high potential for Japanese companies to grow overseas by promoting and marketing their products in the emerging markets of China and other countries. The main challenge is to understand the foreign markets and their regulations to be able to promote Japanese products overseas. Understanding these regulations is an essential step to customize and localize the products to fit the foreign markets. Also, growing overseas has strong benefits for the health sector. Allowing the companies to enhance the R\&D efforts to tackle health related issues in the global markets and boost the innovation in the field of functional food which will directly affect the status of the healthcare sector.

\subsection{Research Questions}

As mentioned in the problem section, the main challenge currently is to find ways to for the Japanese functional food companies to expand abroad. The following research questions address this challenge.

1) What are the key differences in functional food regulations between Japan and other countries?

2) Which international markets can the Japanese products expand to with low adaptation costs and high profitability?

The answers to these questions will create a deeper understanding of the international market and give Japanese companies a competitive advantage for growth in the foreign markets, based on accurate situation analysis.

\subsection{Research Method}

This study conducted a scientific review of the relevant literature and official legislative reports published by the authorized entity in several countries to create a comparison of the rules and regulations in these countries (China, the EU, Korea, Singapore, Taiwan, and the USA). We consider similarities with the Japanese system, as well as differences, and we utilize case studies of actual Japanese products that have been approved internationally. The 
selection of the countries to be studied is based on the significance of those countries in the global functional food market such as having a high market share or distribution level such as USA, Japan and Korea, and also, the potential of those countries as a growing market for functional food such as the case in China.

The comparative study reveals the names of and information about the regulatory agencies, the packaging and information viewing requirements, the purpose of the products in the market, the safety review systems for the products' ingredients, the good manufacturing practice (GMP) system, and intellectual property regulations for each country. In addition, there are requirements and systems for clinical trials, reporting of adverse reactions, obligations to display the certification mark, obligations to display the usage and dosage, and other conditions.

\section{Regulations in Japan}

There is a clear difference between the health food and pharmaceutical categories. While the health food category is specialized in providing food that has been modified or boosted to provide better nutrition, the pharmaceutical category is specialized for products that can treat or prevent diseases.

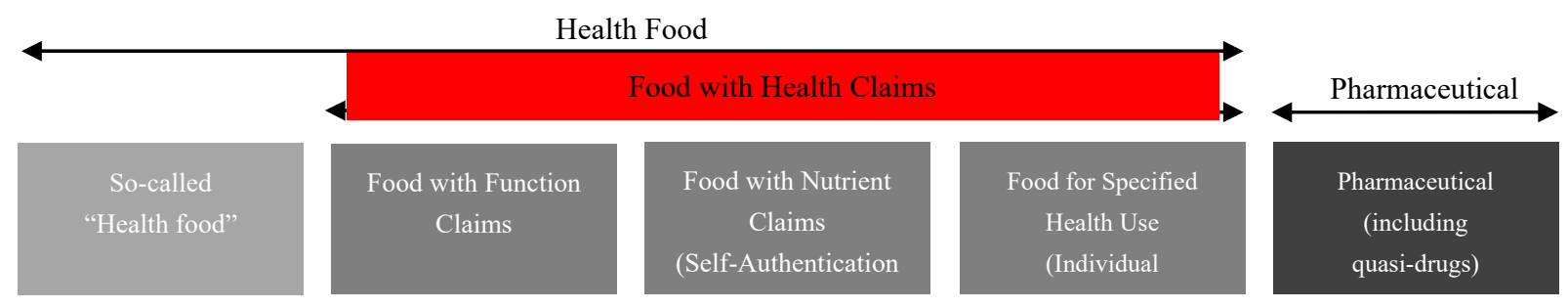

Figure 3. Health and functional food categories in Japan

The health food category consists of two main subcategories. The first one consists of the so-called "health food," which is considered as a grey zone with vague labeling requirements and descriptive definitions. The health and functional food or Food with Health Claims (FHC) category is highly regulated by Japanese authorities, and it is further separated into three subdomains: Food for Specified Health Use (FOSHU), Food with Nutrient Function Claims (FNFC), and Food with Function Claims (FFC) (CAA Food Labeling, 2016).

\subsection{Food for Specified Health Uses (FOSHU)}

The main regulation that governs functional food in Japan is the FOSHU, "Foods for Specified Health Use," also known as TOKUHO which is a Japanese abbreviation for "tokutei hokenyo shokuhin" or foods with special healthy qualities. These rules were introduced by the Ministry of Health, Labour, and Welfare (MHLW) in 1991. This system requires that each product should receive special examination procedures to get approval for labeling. After September $1^{\text {st }}, 2009$, the work related to food labeling was transferred to the Consumer Affairs Agency.

The procedure for approval of this category of functional food uses strict standards, and it requires a substantial financial investment and a lengthy period of review. It poses a challenge of affordability and time-to-market for smaller companies or start-ups, which gives a competitive advantage for large enterprises. These products have specific labeling to display the claim of the product and its functions, for example, indicating ingredients that affect bodily functions (e.g., blood pressure stabilization, cholesterol reduction). In order to get a product approved, the applicant is required to submit the application forms for permission to apply for request for examination. Within the CAA, the permission request is reviewed by three entities; the Consumer Commission, the Food Safety Committee, and the MHLW. The applicant is required to submit a sample of the food product to be inspected by the National Institute of Health and Nutrition or another accredited and registered inspection organization. 


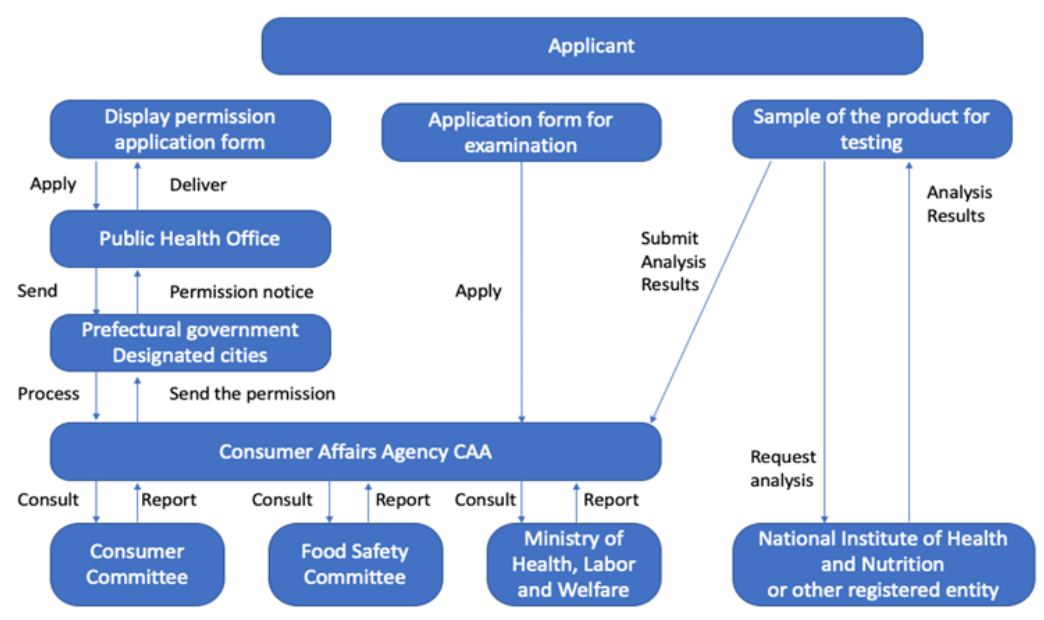

Figure 3. The work process of getting a FOSHU product approval

Source: Consumer Affairs Agency, FOSHU Policy.

\subsection{Food with Nutrient Function Claims (FNFC)}

Another main category of functional food in Japan is the Food with Nutrient Function Claims (FNFC), which was initiated in April 2001. The FNFC includes all foods that have been labeled with nutrient function claims following the standards of the MHLW. Once again, after 2009, the process is controlled by the CAA. The FNFC standards specify twenty main ingredients that may be used, including thirteen vitamins, six minerals, and n-3 fatty acid. The main difference between the FNFC and the FOSHU is that the former does not require any permission from the CAA as long as the product producer guarantees that the product meets the standards and specifications, unlike the accreditation and validation process under FOSHU. The FNFC regulations do not require having a specific logo or certification on the label. However, the nutrient function claims, as well as the warning indications, must be clearly displayed on the product. It is strictly forbidden to label the FNFC products to be useful for a specified health purpose. An example of the FNFC labeling is the identification of the nutritional ingredient as "Vitamin C," with a specified range of advisable daily intake of $24 \sim 1000 \mathrm{mg}$. The functional claims would be "helps to maintain skin and healthy mucosa, and has an anti-oxidizing effect." A warning indication would be, "Increased intake of this product will not result in curing diseases nor promoting health. Please comply with the advisable daily intake." (GAIN report, 2015).

\subsection{Food with Function Claims (FFC)}

Japan also started a new type of regulation in April 2015, named the Food with Function Claims (FFC). This category allows a business to label the food, if the business has submitted a notification to the CAA showing that the products meet national requirements, conform to the safety standards, and show scientific evidence for the functions claimed, obtained from clinical trials with humans to test their effectiveness or from the result of systematic reviews of human studies. The trials must be performed by professionals and experts. The food business operator is required to submit this type of notification to the Secretary-General of the CAA at least sixty days before the launch date or before conducting any marketing campaigns for the product. Also, the products must have labeled packages that comply with the Food Labeling Act and the Guidelines on Notification of Foods with Function Claims. The labeling procedures require the label to be in Japanese and to mention important information such as the main ingredients, the method to use important warnings, recommended daily usage, and the contact information of the manufacturer (CAA Food Labeling, 2016).

This FFC category may be used with all food products, including fresh vegetable produce but excluding products already registered under FOSHU or FNFC; this label also excludes all alcoholic beverages and foods that contain excessive amounts of fat, cholesterol, sugar, and sodium. In the labeling for FFC, keywords that might show or suggest medical benefits such as "treat," "prevent," "diagnose," or "cure" are banned. Also, FFC products may not target a specific segment of consumers who suffer from a certain disease. These products are prohibited from appealing to minors or pregnant women, and they may not claim intentional physical enhancements such as hair growth, bodybuilding, or skin whitening.

For a product to obtain the FFC label, six main procedures are used. The first is to determine the compatibility of 
the product for FFC regulation under the main constraints described above, especially for the labeling process. Second is the evaluation of product safety through safety tests, collecting data into databases, or evaluating actual intake data. The third step is to create a system for manufacturing and product quality control and assurance. Manufacturers are advised to implement Hazard Analysis and Critical Control Points (HACCP) procedures or GMP systems. Fourth is to establish a reporting system to collect data regarding adverse health events. The fifth is the evaluation of product effectiveness by conducting clinical trials or systematic literature reviews. Finally, the manufacturer provides a product label that complies with the standard of "Guidelines on Notification of Foods with Function Claims" (CAA Industry Guide, 2015).

The FFC category provides an accessible way for small businesses to enter the market because it does not require a long and costly process such as FOSHU. Also, it does not require passing assessments. It does give the manufacturer control over product evaluation, unlike the FOSHU.

This new category has sparked a revolution in the functional food industry in Japan. Figure 4 compares the growth in the number of products in the FFC and FOSHU categories. Despite the much more recent start, 172 FCC products were registered in the first year alone. By March 2019, the cumulative number of FFC products reached 1721 , which is surpassing the number of registered FOSHU products in nearly twenty-five years by more than forty percent. We believe that the FOSHU system usage will decrease dramatically over the upcoming years due to the high cost and long examination procedures, and most manufacturers will adopt the FFC system instead, making it become the main system in this field.

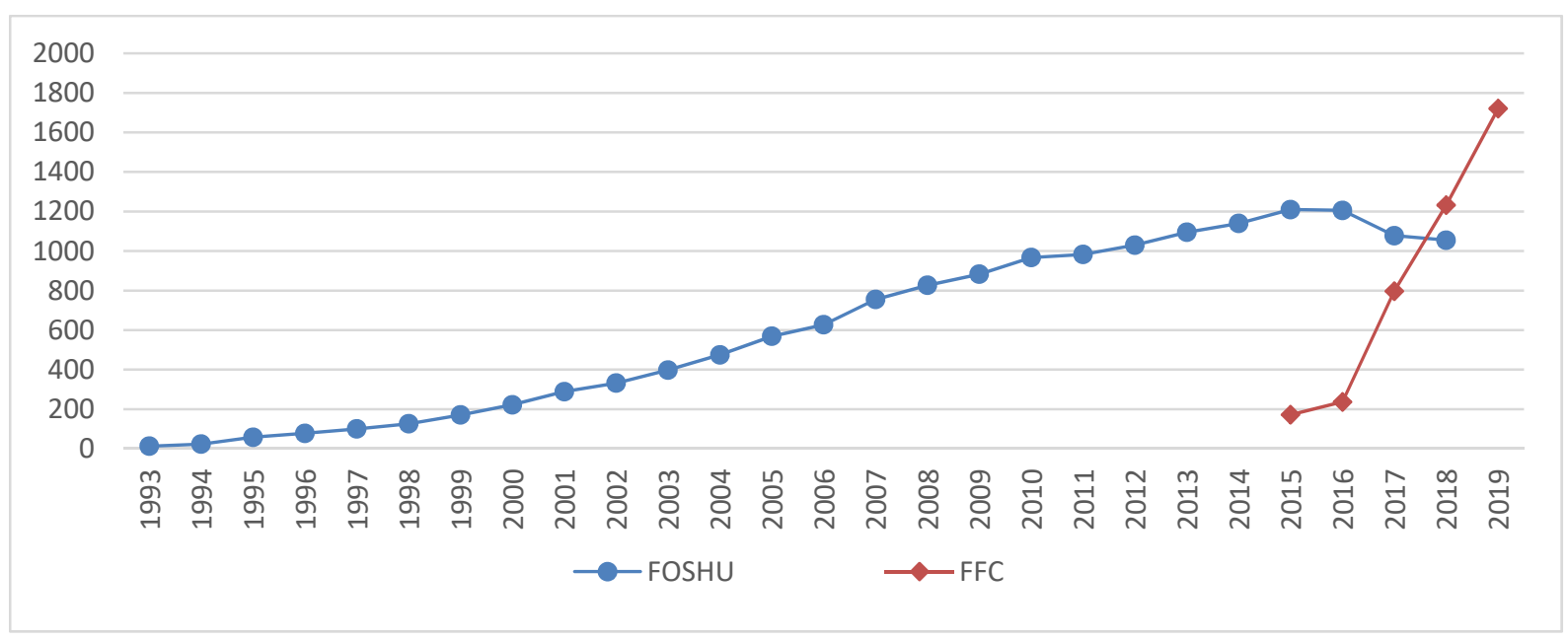

Figure 4. The development of the number of products for FOSHU and FFC (CAA Database, 2019)

\subsection{Japanese local Government Regulation System}

Japanese local governments can certify the functionality of food based on scientific merits, in addition to the national systems. A representative example is the Hokkaido Functional Food Labeling System (Healthy DO), the first accreditation system by a local government in Japan. Healthy DO was launched in 2013, two years before the launch of the Food labeled with Function Claims System (FFC). The purpose of Healthy DO is to promote food-related industries in Hokkaido by raising the value of food and to provide appropriate information in response to consumer needs. A product is eligible for Healthy DO labeling if it satisfies these conditions: (1) it uses functional materials from Hokkaido, (2) it is a processed food product that has been manufactured in Hokkaido, and (3) a peer-reviewed article with results from a human intervention study for the products ingredients has been published. As of February 2019, 113 products manufactured by sixty-one companies have been certified as Healthy DO Products.

A difference between FFC and Healthy DO products is that FFC products need only be reported to the Consumers Affairs Agency CAA, while Healthy DO products need to go through a certification process by the Hokkaido Local Government. For functional foods, it is possible to indicate that it is useful/suitable for maintaining and promoting health but in healthy DO such indications of efficacy are not allowed, and only an indication about scientific evidence for functional material is allowed. Human intervention studies are required in both systems. A clinical study using each final product is required in FFC products. With Healthy DO products, there should be a 
peer-reviewed paper reporting a human intervention study, but it is not necessary to conduct a human intervention study for each final product. Furthermore, foods that lead to high blood sugar levels such as confectionery are not certified with FFC, whereas Healthy DO products do qualify, allowing confectionery and luxury goods to be certified. The Healthy DO and the FFC labels may appear on the same product if the product meets the requirements for both systems. We believe that the local Healthy DO system allows products from small businesses to receive certification easily, opening doors for growth in this field. We believe also that several local governments in Japan will start to adopt systems similar to Healthy DO in order to promote local industries such as Niigata city and Shikoku Island.

\section{Regulations Around the World}

\subsection{Regulatory Agency}

Functional foods are regulated by rules and guidelines specified by the regulatory authority in each country. In the $\mathrm{EU}$, the main regulator for functional foods is the European Commission (EC), which started adopting regulations for the food supplements according to Directive 2002/46/EC of the European Parliament and of the Council of 10 June 2002. In the United States, the regulator is the federal Food and Drug Administration (FDA). The FDA began the labeling scheme for functional foods in 1991, also it has issued the Dietary Supplement Health and Education Act of 1994 (DSHEA). In Korea, the regulator is the Ministry of Food and Drug Safety (MFDS), which crafted the Health Function Food Act in May 2004. In Taiwan, there is the Taiwan Food and Drug Administration (TFDA). In China, the responsible entity is the Chinese Food and Drug Administration, which has issued the first law for functional food in 1996, also, finalized detailed rules for health food application filing and it began a new official process to accept health food filing application in May 2017. In Singapore, the regulator is the Health Sciences Authority (HAS). In Japan, the CAA is the entity responsible.

\subsection{Product Categorization}

There is a significant difference between functional food and pharmaceutical production rules and regulations. The development process is different along with the validation and authorization process as well. All the countries mentioned above have created specific laws, regulations, and standards for functional or health foods that are independent of laws and regulations concerning pharmaceuticals. The countries recognize functional foods as a specific type of food products, even a separate regulatory does not exist. This is true for the Food and Drug Administration in the USA.

\subsection{Shape Description}

Functional food products can come in different shapes such as capsules or tablets. Each has different dissolution characteristics and dosage forms. At the time that a capsule usually contains powder or jelly, tablets compress the powder in a solid form. Regarding effectiveness, capsule contents tend to enter the bloodstream much faster than the ingredients in tablets, all the more so if the tablets are coated with substances that slow delivery to the bloodstream. Capsules also tend to have a shorter shelf life than the tablets, making tablets a better option for long-term storage.

It is important to understand labeling regulations in terms of functional food packaging. Specifying the form of the product (tablets, capsules) is required in the EU, Singapore, and USA. However, such a description is not required in Korea, Japan, and Taiwan. In China, the shape of the product is often but not always displayed on all the product. If a manufacturer produces packages of functional food export to the EU, Korea, Singapore, or the USA. that manufacturer should comply with labeling requirements by displaying the shape of the product.

\section{4 Product Purpose}

There is a clear distinction between the regulation of functional foods and pharmaceutical products in the purpose of use and market-related information. In most cases, pharmaceuticals are marketed as cures or treatments for specific diseases. In contrast, functional foods tend to be marketed as supplements or as sources of boosted nutrients. In the countries that we have compared (EU, USA, Korea, Taiwan China, Singapore, and Japan), functional food marketing campaigns and labels should only convey the message of being food supplements or boosted vitamins and nutrients. These may not be marketed as products that provide treatment for any medical condition. This should not create any type of challenges for Japanese export since Japan already adheres to the same regulatory distinction.

\subsection{Positive List}

A common approach by regulatory authorities to ensure the safety of functional food ingredients is the creation of a "positive list." Regulations call for clear identification of permissible ingredients, and regulators provide a 
positive list that contains the names of the vitamins, minerals, and other substances that have been approved for use in functional foods, along with their permissible sources. Some countries also provide a negative list that has potential ingredients that are not allowed in a functional food product (FSAI, 2007). In the countries that we have compared, we have found that China, the EU, Korea, Singapore, and Taiwan, provide a specific positive list with the allowed components, while the USA do not provide such a list. Interestingly, Japan provides both a specific positive list and a negative list. While the existence of the positive list and the negative list might create some limitation for manufacturers in terms of the ingredients that can be used, they do provide a clear aid for manufacturers to gain certification or validation for their products in global markets.

\subsection{Good Manufacturing Practice GMP System}

To ensure that the products are manufactured with high safety and quality level, most manufacturers of functional food products tend to adopt the Good Manufacturing Practice (GMP) system. The system ensures that the manufacturing process complies with the required regulations. The GMP application is not limited to manufacturers only; it can expand to cover the facilities responsible for packaging and labeling, as well as the distribution centers and storage facilities. This system creates an assurance for the consumer that the product has the highest level of safety, integrity, strength, purity, quality, and composition (SISPQC). The GMP system is not limited to the product manufactured only. It focuses on the entire production environment, covering all the premises needed for product commercialization, the quality assurance of the personnel who participated in creating the products, and the different processes used by the manufacturer (Debasis, 2014).

The GMP system differs from country to country. We have found that the USA, Korea, Taiwan, and China have dedicated GMP systems for manufacturing functional food products. The EU has HACCP and food GMP according to the food general law. Japan has the HACCP requirement according to the Food Sanitation Act. However, Japan and Singapore do not require a specific GMP for functional foods.

\subsection{Intellectual Property and Patent Utility Model}

The Patent and Utility Model Examination Standards of the Japanese Patent Office were revised, and operations to protect originality for the known food products was started on April 1, 2016.

In the past, even when new attributes discovered in known foods (i.e., manufacturers had not recognized these attributes or used them for marketing), manufacturers' rights to intellectual property were refused. Due to growing health consciousness and the increasing popularity of functional foods, there has been a growing pressure to include novel attributes and uses under existing patents and rights. The Patent Office decided to expand manufacturers' rights when the use of food changes from its original use due to the discovery of new food attributes. This applies when the subject of the patent is claimed to be the discovered/invented attribute which is a compound, a microorganism, a plant or an animal and is not considered as a novelty.

As an example, if the component in the food product claims for "periodontal disease prevention" and contains ingredient A as an active ingredient, the food composition is "beverage composition", "grapefruit juice", the novelty is recognized for the patent. On the other hand, when the component/attribute is "grapefruit" or another plant, intellectual property is not considered a novelty.

In addition, if there is no description of tests concerning the effect due to the reason that it is not possible to predict the effect even in light of technical common sense, it can be refused for a patent (Violation of Article 36, Paragraph 4, Item 1 or 6 of the Patent Act). In order to support technical common sense, the applicant should submit the experimental results certificate after application, but this cannot compensate for the deficiencies in the description requirements.

The invention of the method relating to the new method of utilizing publicly known foods falls under medical usage in principle. As for the industrial usage, it is subject to refusal (violation of Article 29 of the Patent Law).

When comparing the patent system, when the food itself is a novelty, it can be patented in Japan, the United States, and Europe as an invention. Regarding the invention of the usage of known foods, it is possible to recognize the novelty in Japan and Europe, but in the United States, novelty without the limited usage can be the reason for refusal. However, since substances or compositions used for medical practice are subject to protection in Europe when the application falls under medical practice such as improving health, the novelty is decided by considering the limited usage of the substance or composition (European Patent Convention Article 54 (4)). Regarding the invention of the new method of utilizing publicly known food products, it is not protected in Japan and Europe when it falls under medical practice and has reasons for refusal; in the United States, the same medical practice can be protected as a methodical invention (Chong et al., 2008). 
Table 4. Comparison of the main factors of the functional food regulations across the World

\begin{tabular}{|c|c|c|c|c|c|c|c|}
\hline Item & $E U$ & $U S$ & Korea & Taiwan & China & Singapore & Japan \\
\hline Regulatory Agency & $\mathrm{EC}$ & FDA & MFDS & TFDA & CFDA & HSA & CAA/MHLW \\
\hline $\begin{array}{l}\text { Food / Medicine } \\
\text { Category }\end{array}$ & Food & Food & Food & Food & Food & Food & Food \\
\hline $\begin{array}{l}\text { Shape description } \\
\text { (tablet, etc.) }\end{array}$ & Yes & Yes & No & No & Often & Yes & No \\
\hline $\begin{array}{l}\text { Purpose: Supplement of } \\
\text { meals }\end{array}$ & Yes & Yes & Yes & Yes & Yes & Yes & Yes/No \\
\hline $\begin{array}{l}\text { Purposes: Treatment } \\
\text { and improvement of } \\
\text { diseases }\end{array}$ & No & No & No & No & No & No & No \\
\hline $\begin{array}{l}\text { Registration / Approval } \\
\text { System (Business Item) }\end{array}$ & Yes & No & Yes & Yes & Yes & No & $\begin{array}{l}\text { In } \\
\text { parallel }\end{array}$ \\
\hline $\begin{array}{l}\text { Safety review system } \\
\text { for the ingredients (raw } \\
\text { materials) }\end{array}$ & Yes & Yes & Yes & Yes & Yes & Yes & Depends \\
\hline Presence of positive list & Yes & No & Yes & Yes & Yes & Yes & No \\
\hline GMP system by country & Yes & Yes & Yes & Yes & Yes & No & No \\
\hline $\begin{array}{l}\text { Clinical trials of } \\
\text { individual products }\end{array}$ & $\begin{array}{l}\text { For new } \\
\text { ingredient }\end{array}$ & No & Depends* & Depends & $\begin{array}{l}\text { New } \\
\text { Ingredient }\end{array}$ & No & Depends \\
\hline $\begin{array}{l}\text { Adverse reaction } \\
\text { reporting system }\end{array}$ & Yes & Yes & Yes & No & No & No & Yes** \\
\hline $\begin{array}{l}\text { Obligated to display the } \\
\text { category name }\end{array}$ & Yes & Yes & Recommended & Yes & Yes & Recommended & Depends \\
\hline $\begin{array}{l}\text { Obligations to display } \\
\text { the certification } \\
\text { mark/approval number } \\
\text { of the country }\end{array}$ & No & No & Recommended & Yes & Yes & No & Depends*** \\
\hline $\begin{array}{l}\text { Obligated to display the } \\
\text { usage and dosage }\end{array}$ & Yes & Yes & Yes & Yes & Yes & Recommended & Recommended \\
\hline
\end{tabular}

Source: Created by authors and combined from different referenced sources.

* Clinical Study on raw materials is essential.

** According to the amendment of the Food Sanitation Act. On June 13, 2018.

*** FOSHU \& FFC require to display when FNFC does not require that.

\section{Summary}

The functional food global market size is continuously growing, especially with the increase of the elderly populations and the increase of life expectancy. Consumers in several markets around the world started to become more educated about the benefits of functional foods, fueled by an increase in disposable income. The Asia-Pacific market is the leading regional market in the world for functional foods generating nearly $40 \%$ of global revenues in 2017 , and it is also highly expected to have a compound annual growth of nearly $8 \%$ over the upcoming six years.

The Japanese market is also expected to experience growth because of with the creation of the new category, FFC, which has made the labeling process easier for manufacturers, compared to FOSHU requirements that require the products to pass certain tests and inspections. We expect that the FFC will become the main regulatory process in Japan, under which companies will market their products while they are preparing to obtain the FOSHU licenses.

After studying the rules and regulations in different countries, the study has shown that, in the United States, compliance with various certifications and the disclosure of product information are indispensable. Applying these 
measures comes with a very high cost which may pose challenges for Japanese products in American markets. The Singaporean market has fewer restrictions, and it is considered to be an attractive market.

China also is considered a vast and growing market. The Chinese market is shifting towards functional foods due to several health threats and the rise of non-communicable diseases such as obesity. China also has a large segment of seniors. The above-mentioned reasons make China an attractive market for Japanese products. It is highly recommended to start promoting the products listed in the positive list of each country as China has much lower development costs, as well as targeting countries fewer entry barriers. We also recommend further negotiations with the authorized agencies of each country to facilitate and accelerate the promotion of the products in order to forestall uncertainties.

Another way to enter a critical and complex market such as the United States is through target sales of the functional food product. The American functional food market is growing by $10 \%$ yearly, and it requires a continual supply of the main ingredients. The global functional food ingredients market is nearly 67 billion USD in 2017 , and it is expected to have a compound annual growth of $6.7 \%$ over the upcoming years (Data Bridge, 2017).

The results also could be utilized by small start-up companies who are shaping and revolutionizing the future of the food. The research provides the start-ups with essential information to develop new products or solutions for the foreign markets by cooperating with manufacturers in this field.

\section{Competing Interests Statement}

The authors declare that there are no competing or potential conflicts of interest.

\section{Acknowledgments}

We acknowledge the support from JSPS KAKENHI Grant Numbers JP15H05183. We also appreciate all open-source and database developers used in this research.

\section{References}

A Guide to Food Labeling and Advertisements, A publication of the Agri-Food \& Veterinary Authority, Singapore, First published Feb 2010. Amendments Oct 2011, Oct 2013, Jul 2014, Jan 2015, Jul 2015, Mar 2016, Aug 2018, Feb

2019 , https://www.ava.gov.sg/docs/default-source/tools-and-resources/resources-for-businesses/aguidetofoodlabel ingandadvertisementsversionjuly2.pdf

Bagchi, D. (Ed.). (2008). Nutraceutical and functional food regulations in the United States and around the World (2nd ed.). Debasis Bagchi, Food science and technology international series. Academic Press. https://doi.org/10.1016/B978-0-12-373901-8.X0001-7

Blandon, J., Cranfield, J., \& Henson, S. (2007). Functional Food and Natural Health Product Issues: The Canadian and International Context. International Food Economy Research Group Department of Food, Agricultural and Resource Economics, 1-55.

Bröring, S., \& Khedkar, S. (2018). Regulatory Compliance and Company Strategies: The Case of the Nutrition and Health Claims Regulation (EC) No. 1924/2006. In Regulating and Managing Food Safety in the EU (pp. 105-128). Springer, Cham. https://doi.org/10.1007/978-3-319-77045-1_6

CAA Policies, FOSHU Database. (2019). Retrieved from https://www.caa.go.jp/policies/policy/food_labeling/health_promotion/pdf/health_promotion_190415_0001 .xls

Chong, L. K., Udell, L. J., \& Downs, B. W. (2008). Intellectual Property, Branding, Trademark and Regulatory Approvals in Nutraceuticals and Functional Foods. In Nutraceutical and Functional Food Regulations in the United States and Around the World (pp. 403-416). Academic Press. https://doi.org/10.1016/B978-012373901-8.00025-1

Consumer Affair Agency, food labeling policy. Retrieved from https://www.caa.go.jp/policies/policy/food_labeling/health_promotion/

Daliri, E. B. M., \& Lee, B. H. (2015). Current trends and future perspectives on functional foods and nutraceuticals. In Beneficial microorganisms in food and nutraceuticals (pp. 221-244). Springer, Cham. https://doi.org/10.1007/978-3-319-23177-8_10

EU Publications, Functional Food Report, 2010, Directorate-General for Research and Innovation (European Commission), ISSN 1018-5593, DOI 10.2777/82512 
Euro Monitor (2013 Report). Global Consumer Trends. Retrieved from https://www.euromonitor.com

Functional Food Ingredients Market 2019 Synopsis, Market Surge, Future Scope, Top Key Players and Forecast to 2025. Retrieved from https://wiseawareness.com/functional-food-ingredients-market-2019-synopsis-market -surge-future-scope-top-key-players-and-forecast-to-2025/

Functional Foods In The European Union: An Overview Of The Sector's Main Issues, Alessandra Castellini, Maurizio Canavari, and Carlo Pirazzoli. (2002). 8th Joint Conference on Food, Agriculture and the Environment.

Global Health Functional Food Market Insights, Forecast To 2025, Big Market Research. (2018). Retrieved from https://www.bigmarketresearch.com/global-health-functional-food-insights-forecast-to-2025-market

González-Díaz, C., Gil-González, D., \& Álvarez-Dardet, C. (2018). Scientific evidence on functional food and its commercial communication: A review of legislation in Europe and the USA. Journal of food science, 83(11), 2710-2717. https://doi.org/10.1111/1750-3841.14359

Gur, J., Mawuntu, M., \& Martirosyan, D. (2018). FFC's Advancement of Functional Food Definition. Functional Foods in Health and Disease, 8(7), 385-297. https://doi.org/10.31989/ffhd.v8i7.531

Hasler, C. M. (2002). Functional foods: benefits, concerns and challenges - a position paper from the American Council on Science and Health. The Journal of nutrition, 132(12), 3772-3781. https://doi.org/10.1093/jn/132.12.3772

Hasler, C. M. (Ed.). (2005). Regulation of functional foods and nutraceuticals: a global perspective (Vol. 5). John Wiley \& Sons.

Japan's New Health Claims Labeling System Creates Opportunities. (2015). GAIN Report Number: JA5025, USDA Foreign Agricultural Service, Yuichi Hayashi. Retrieved from https://gain.fas.usda.gov

Khedkar, S., Ciliberti, S., \& Bröring, S. (2016). The EU health claims regulation: implications for innovation in the EU food sector. British Food Journal, 118(11), 2647-2665. https://doi.org/10.1108/BFJ-01-2016-0021

Kim, J. Y., Kim, D. B., \& Lee, H. J. (2006). Regulations on health/functional foods in Korea. Toxicology, 221(1), 112-118. https://doi.org/10.1016/j.tox.2006.01.016

Lalor, F., \& Wall, P. G. (2011). Health claims regulations: comparison between USA, Japan and European Union. British Food Journal, 113(2), 298-313. https://doi.org/10.1108/00070701111105358

Malla, S., Hobbs, J. E., \& Sogah, E. K. (2013). Functional foods and natural health products regulations in Canada and around the world: nutrition labels and health claims. Saskatoon, Saskatchewan, Canada: Report prepared for the Canadian Agricultural Innovation and Regulation Network, 447-454.

Martirosyan, D. M., \& Singharaj, B. (2016). Health claims and functional food: The future of functional foods under FDA and EFSA regulation. Functional Foods for Chronic Diseases; Food Science Publisher: Dallas, $T X, U S A, 410-424$.

Mishra, S. S., Behera, P. K., Kar, B., \& Ray, R. C. (2018). Advances in probiotics, prebiotics and nutraceuticals. In Innovations in Technologies for Fermented Food and Beverage Industries (pp. 121-141). Springer, Cham. https://doi.org/10.1007/978-3-319-74820-7_7

Miura, T. (2017). Food functional display system in Hokkaido: Current status of Healthy DO (Vol. 21 No. 1, pp.1-4). [In Japanese]

Moors, E. H. (2012). Functional foods: regulation and innovations in the EU. Innovation: The European Journal of Social Science Research, 25(4), 424-440. https://doi.org/10.1080/13511610.2012.726407

Ohama, H., Ikeda, H., \& Moriyama, H. (2008). Health foods and foods with health claims in Japan. In Nutraceutical and functional food regulations in the United States and around the world (pp. 249-280). Academic Press. https://doi.org/10.1016/j.tox.2006.01.015

Patel, D., Dufour, Y., \& Domigan, N. (2008). Functional food and nutraceutical registration process in Japan and China. Similarities and differences. J Pharm Pharmaceut Sci, 11(4), 1-11. https://doi.org/10.18433/J32S3N

Ross, S. (2000). Functional foods: the Food and Drug Administration perspective. The American journal of clinical nutrition, 71(6), 1735S-1738S. https://doi.org/10.1093/ajcn/71.6.1735S

Shimizu, M. (2014). History and Current Status of Functional Food Regulations in Japan. Nutraceutical and Functional Food Regulations in the United States and Around the World (2nd ed., pp. 257-263). 
https://doi.org/10.1016/B978-0-12-405870-5.00015-3.

Shimizu, M. (2017). Multifunctions of dietary polyphenols in the regulation of intestinal inflammation. journal of food and drug analysis, 25(1), 93-99. https://doi.org/10.1016/j.jfda.2016.12.003

Shimizu, T. (2003). Health claims on functional foods: the Japanese regulations and an international comparison. Nutrition research reviews, 16(2), 241-252. https://doi.org/10.1079/NRR200363

Siegrist, M., Shi, J., Giusto, A., \& Hartmann, C. (2015). Worlds apart. Consumer acceptance of functional foods and beverages in Germany and China. Appetite, 92, 87-93. https://doi.org/10.1016/j.appet.2015.05.017

Singh, R. B., Takahashi, T., Shastun, S., Elkilany, G., Hristova, K., Shehab, A., ... \& Srivastava, R. K. (2015). The concept of functional foods and functional farming $(4 \mathrm{~F})$ in the prevention of cardiovascular diseases: A review of goals from 18th World Congress of Clinical Nutrition. Journal of Cardiology and Therapy, 2(4), 341-344. https://doi.org/10.17554/j.issn.2309-6861.2015.02.75

Tanemura, N., Hamadate, N., \& Urushihara, H. (2018). Evaluation of randomized controlled trials of foods with functional claims request: The learning outcomes from studies in Japan. Journal of functional foods, 42, 248-253. https://doi.org/10.1016/j.jff.2017.12.066

The World Bank Database, Age dependency ratio, age distributions of United Nations Population Division's World Population, https://data.worldbank.org/share/widget?indicators=SP.POP.DPND\&view=chart

Villaño, D., Gironés-Vilapana, A., García-Viguera, C., \& Moreno, D. A. (2016). Development of Functional Foods. In Innovation Strategies in the Food Industry (pp. 191-210). Academic Press. https://doi.org/10.1016/B978-0-12-803751-5.00010-6

Yamada, K., Sato-Mito, N., Nagata, J., \& Umegaki, K. (2008). Health claim evidence requirements in Japan. The Journal of nutrition, 138(6), 1192S-1198S. https://doi.org/10.1093/jn/138.6.1192S

\section{Appendix A}

\section{List of abbreviations}

$\begin{array}{ll}\text { JPY } & \text { Japanese Yen } \\ \text { USD } & \text { United States Dollar } \\ & \\ \text { USA } & \text { United States of America } \\ \text { UK } & \text { United Kingdom } \\ \text { EU } & \text { European Union } \\ \text { EC } & \text { European Commission } \\ & \\ \text { \$T } & \text { Trillions of American Dollars } \\ \text { \$B } & \text { Billions of American Dollars } \\ \text { \$K } & \text { Thousands of American Dollars } \\ \text { M } & \text { Million }\end{array}$

PLC Public Limited Company

S. Societas Europaea, public company registered in the EU

INC Incorporated Company

FHC Food with Health Claims

FOSHU Food for Specified Health Use

FNFC Food with Nutrient Function Claims 
FFC Food with Function Claims

TOKUHO Japanese for "tokutei hokenyo shokuhin" equivalent to FOSHU

MHLW Ministry of Health, Labour and Welfare

CAA Consumer Affairs Agency

FDA Food and Drug Administration

MFDS Ministry of Food and Drug Safety

TFDA Taiwan Food and Drug Administration

HSA Health Sciences Authority

CFDA China Food and Drug Administration

R\&D Research \& Development

GMP Good Manufacturing Practice

HACCP Hazard analysis and critical control points

SISPQC Safety, identity, strength, purity, and quality

\section{Copyrights}

Copyright for this article is retained by the author(s), with first publication rights granted to the journal.

This is an open-access article distributed under the terms and conditions of the Creative Commons Attribution license (http://creativecommons.org/licenses/by/4.0/). 